\title{
Intervenção urbana esportiva: notas etnográficas sobre o grupo Rizoma
}

CDD. 20.ed. 306

796.05

http://dx.doi.org/10.1590/1807-55092015000100081

\author{
Leandro de Araújo COSTA ${ }^{* * * *}$ \\ Renata OSBORNE** \\ Roberto Ferreira dos SANTOS ${ }^{* *}$ \\ Carlos Henrique de Vasconcellos RIBEIRO*** \\ *Prefeitura Municipal \\ do Rio de Janeiro. \\ ${ }^{* *}$ Universidade Salga- \\ do de Oliveira. \\ ***Fundação de Apoio \\ à Escola Técnica.
}

\section{Resumo}

0 objetivo deste trabalho foi analisar as formas alternativas de ações esportivas realizadas por um grupo de jovens que pretendem contrariar visões reducionistas do esporte relacionadas ao capitalismo contemporâneo e, assim, apresentam sua visão crítica do sistema através da intervenção urbana esportiva. A pesquisa utilizou como metodologia qualitativa o estudo de caso etnográfico, empregando os instrumentos de coleta de dados: observação participante, entrevista individual e de grupo e análise de documentos. Visto que o esporte nos fornece possibilidades estéticas em diferentes dimensões, e não apenas aquela consumivel pelo mercado, nós podemos pensá-lo como uma manifestação cultural cuja singularidade não está confinada apenas na indústria do entretenimento esportivo.

Palavras-chave: Cultura; Estudo de caso; Esporte; Espaço público.

\section{Introdução}

$\mathrm{Na}$ infância, o movimento para a criança é um aprendizado constante motivado por suas potencialidades biológicas e pelos estímulos fornecidos pelos que a cercam. A criança aprende a cultura na qual está imersa, experimentando, brincando criativamente com tudo que lhe é permitido. À medida que cresce, sua criatividade vai ora sendo cerceada, ora sendo estimulada, mas nos parece que o contexto vai moldando o ser humano.

A cultura para GEerTz 1 é compreendida como a própria condição de vida de todos os seres humanos, produto das açôes, como um processo contínuo pelo qual as pessoas dão sentido às suas realizaçôes. Ela é universal porque todos os seres humanos produzem, mas é também local, uma vez que é a dinâmica específica de vida que significa o que o ser humano faz, constituindo-se em processo singular e privado, mas também plural e público. Neste sentido, Daolio ${ }^{2}$ afirma que a cultura ocorre na mediação entre os indivíduos, onde se manipulam padróes de significados que fazem sentido num contexto específico.

$\mathrm{Na}$ década de 80 o debate acadêmico na área da Educação Física era predominantemente das ciências biológicas. O corpo era visto somente como um conglomerado de ossos e músculos e náo como expressão da cultura. Considerando o corpo como uma máquina passível de intervenção técnica, priorizava-se a dimensão da eficiência, perdendo a possibilidade de observá-lo como produtor e expressão de cultura, o que levou ao distanciamento dos universos simbólicos, estéticos e subjetivos ${ }^{2}$. Ao ampliar e validar mais essa discussão acerca da cultura e das manifestaçóes que as envolvem o autor é peremptório:

Tenho afirmado em outros trabalhos que 'cultura’ é o principal conceito da educação física, porque todas as manifestaçôes culturais humanas são geradas na dinâmica cultural, desde os primórdios da evolução até hoje, expressando-se diversificadamente e com significados próprios no contexto de grupos culturais específicos. O profissional de Educação Física não atua sobre o corpo ou com o movimento em si; não trabalha com o esporte em si; não lida com a ginástica em si. Ele trata do ser humano nas suas manifestaçōes culturais relacionadas ao corpo e ao movimento humano $[\ldots]^{2}$ (p.2). 
Convivemos com o esporte de uma forma aparentemente espontânea, como se fôssemos nós os seus criadores, mas ele nos é apresentado pela sociedade em que vivemos. Seria mesmo impossível imaginar crescermos sem esse contato precoce e ao mesmo tempo, tão definitivo com a experiência esportiva. $O$ pensamento dominante quanto às atividades esportivas vincula-se ora ao entretenimento, com características para alto rendimento ora à saúde. Tal fato é alimentado na sociedade contemporânea pelos discursos midiáticos, que assumem esse papel com um conjunto de interesses próprios que se articulam, trazendo influências sobre o cotidiano social e individual. Em nossa opinião, menos ênfase tem sido dada ao esporte educacional ou ao seu uso político ou às possibilidades de desenvolver a criatividade humana usando o esporte como veículo.

Fatores históricos como a expansão do modelo esportivo inglês no final do século XX ao movimento olímpico divulgado através das camadas sociais abastadas pelo Barão de Coubertin contribuíram para a divulgação de valores ideológicos do liberalismo e do modo de produção capitalista.

Hoje em dia no Brasil, A Copa do Mundo de Futebol (2014) e os Jogos Olímpicos de 2016 são exemplos de como instituiçóes esportivas internacionais aliadas a estratégias de "marketing" e financiadores privados ditam as regras em um país, para atender aos seus interesses econômicos em detrimento de aspectos sociais e culturais locais. A FIFA e os patrocinadores da Copa, por exemplo, pressionaram o governo brasileiro para permitir a venda de bebidas alcoólicas nos estádios de futebol durante os jogos da Copa. O governo, então criou uma lei para atender ao desejo da FIFA, que tem como um dos principais patrocinadores da Copa uma cerveja americana.

Outro exemplo são as vuvuzelas, cornetas que os torcedores levam aos estádios da África do Sul, que foram alvo de críticas durante a transmissão das partidas pela TV na Copa da África do Sul. Assim, outros instrumentos de uso dos torcedores brasileiros não foram permitidos nos estádios, para não prejudicar o andamento dos jogos e transmissóes. Dessa forma, os costumes locais são cerceados.

Para multiplicar os consumidores/espectadores, a mediação é realizada pelos meios de comunicaçáo, que exigem novos profissionais nesse campo. $\mathrm{O}$ "mass media" (mídia de massa) de "marketing" esportivo "passa a 'pensar' o esporte como uma mercadoria simbólica, cuja imagem (movimentos corporais humanos, emoçôes, valores sociais e ideológicos) precisa vender, ainda, a 'necessidade' de consumo dos produtos disponibilizados ${ }^{3}$ (p.31).
Em contraponto a atitudes de ordem mercadológica que tentam "vender" ou naturalizar conceitos artificiais através de uma indústria do entretenimento, surge uma forma alternativa de resistência, as Intervenções Urbanas. Estas, alicerçadas nos movimentos contraculturais da década de 60 , que questionavam os valores da cultura ocidental, através de diversas atividades criativas, tentam gerar inquietação em vez de passividade social. As intervençôes urbanas são bastante conhecidas até mesmo aos transeuntes mais incautos, como o grafite que por meio de inscriçóes ou desenhos realizados com tinta aerossol tornam-se cada dia mais comuns em muros e viadutos das grandes cidades, assim como grupos teatrais ou das artes plásticas que realizam nos espaços públicos cenas ou expóem suas obras.

$\mathrm{O}$ aparecimento de grupos que utilizam as atividades esportivas como forma de manifestaçâo demonstra a enorme possibilidade que a intervenção urbana pode trazer para o processo de comunicação. Um grupo radicado na cidade do Rio de Janeiro realiza uma série de eventos que podemos caracterizar como intervenção urbana. Porém, o que chamou a nossa atenção neste grupo em especial foi o uso de atividades físicas de caráter esportivo como instrumentos para suas açóes.

Cinco jovens moradores da região da Tijuca, praticantes das mais diversas atividades esportivas, formam um grupo que realiza suas açóes as quais intitularam de intervençôes urbanas e as filmam colocando-as em seu "blog" canalrizoma.blogspot. com. O grupo procura dar visibilidade aos problemas cotidianos vividos em uma metrópole, frutos do descaso da sociedade e do poder público, através de intervençôes lúdicas, realizando atividades esportivas que sempre utilizam como cenário a cidade e seus diversos (e até incomuns) percursos.

Suas açôes são realizadas em meio urbano e sem aviso prévio de onde e como ocorrerão. Contudo, a utilização da mídia digital possibilita que a intervenção alcance um grande potencial de divulgação, pois náo fica restrito apenas ao número de transeuntes que presenciam o momento da ação.

Compreender as relaçóes entre a cidade e seus habitantes por meio de sua interação pressupóe partir do âmbito da cultura, ou seja, das experiências compartilhadas, da sensibilidade estética das práticas cotidianas, dos pertencimentos e construçóes identitárias, do universo simbólico e do imaginário comum aos grupos e sujeitos, como propôs OLIVEIRA ${ }^{4}$.

Assim, o objetivo deste artigo foi analisar a prática esportiva na forma de intervenção urbana como modo de manifestação cultural. 


\section{Referencial teórico}

\section{A intervenção urbana}

Os movimentos de intervenção urbana tendem a produzir uma politização do cotidiano e do espaço público, e assim instaura um distanciamento da política institucional tendo a cultura e a reprodução social como terreno de combate. Não obstante, destacam a ação direta para fomentação de visóes utópicas, na busca por produzir novas maneiras de ver, sentir, perceber, ser e estar no mundo, características apresentadas para a classificação de uma intervenção por MAZETTI ${ }^{5}$.

Há inúmeras formas de intervir com arte na natureza ou na paisagem, seja ela urbana ou rural, como aponta BARJA ${ }^{6}$. Para o autor o conceito de natureza "parte de sua espontânea presentificação ambiental, sem um planejamento prévio. Já a paisagem admite um locus, ou seja, uma lógica espacial, pensada de forma a organizá-la para gerar um lugar idealizado"6 (p.213).

As intervenções urbanas não significam a busca por tomar os meios de produção da informação, ou seja, assumir o papel do emissor no processo de comunicação, mas a proposição de jogo lúdico nos espaços já dados. Isto significa que tais atividades "não buscam ocupar, interromper ou destruir os canais dominantes de comunicação, mas desviar e subverter as mensagens por eles levadas"a,7 (p.87).

A partir desta perspectiva de resistência, a prática esportiva na forma de intervenção urbana como modo de manifestação pública do Grupo Rizoma demonstra a importância da utilização desta forma de mídia. Como exemplo, uma de suas intervençóes chamou-se "Rafting no Rio Maracanã" que pode ser visualizada no "blog" do grupo e no "youtube", tendo tido 1373 acessos de fevereiro a meados de agosto do ano de 2010. Porém, o número total de pessoas que assistiram a esta ação não pode ser contabilizado apenas pela quantidade de acessos mencionados porque a ação foi apresentada no Canal Sport TV, no programa Zona de Impacto, o que aumenta significativamente o acesso de pessoas à visualização desta ação.

\section{A contracultura e o efeito midiático}

Segundo Mazetri ${ }^{5}$, as intervenções urbanas se colocam de forma crítica na sociedade e têm a proposta de "extrapolar a experimentação estética numa união entre arte e vida” (p.124). Elas buscam inspiração em movimentos artísticos iniciados no surrealismo e no Dadá-Berlim ${ }^{\text {. }}$
"Há um caminho que liga as experimentaçóes formais na arte, os movimentos contraculturais $\mathrm{da}$ década de 60, até as práticas comunicacionais subversivas de coletivos, como grupos de intervenção urbana e outras formas de ativismo midiático [...]" (Home citado por MazetTi ${ }^{5}$, p.125).

Nas açóes contraculturais, procura-se criar "meios" para gerar uma inquietação em vez da passividade social. As novas formas alternativas de intervençôes submeteram e atraíram a atenção popular, dos grafites em Maio de 68 (França), o "sticker" e o "stencil"d em diversas revoltas juvenis, aos teatros de guerrilha ${ }^{\mathrm{e}}$.

São alternativas em que a participação consegue ultrapassar as barreiras do convencional, do racional e do "audiovisual" estabelecendo um diálogo com o cotidiano e contestando o sistema. Todas essas formas de contestação têm a mídia como forma de divulgação e informação. Se a comunicação agride os movimentos de contestação ao diluí-los e transformá-los em assunto de moda, existe uma contrapartida das intervençōes urbanas, ao se apresentarem em sua forma mais agressiva, alterando os símbolos do capitalismo ${ }^{8}$.

Quando pensamos em manifestaçóes culturais, consideramos todas as manifestações que caracterizam, identificam e representam a cultura de um povo ou nação, cada uma com suas determinadas particularidades e princípios, sem qualquer tipo de censura ou proibição moral, exercidas pela liberdade plena de opinião e pensamento 9 . Tal definição, apesar de muito abrangente, procura contemplar as características que constituem estas manifestaçôes.

A atividade esportiva pode ser considerada, atualmente, a principal manifestação da nossa cultura de movimento e das práticas corporais que nos envolvem. Num passado recente (menos de um século atrás) os jogos, as brincadeiras e a ginástica representavam as nossas formas simbólicas de dialogar com o mundo e conosco mesmo ${ }^{10}$. Não há dúvidas da importância que o esporte adquiriu na sociedade contemporânea.

Deve-se considerar a cidade ou um determinado lugar, como um receptor não-fixo e não passivo, mas variável e de caráter transitório, um multiplicador capaz de trazer ao projeto de intervenção um alto grau de visibilidade e interatividade com seus componentes espaciais e humanos. Neste contexto, deve ser levado em conta elementos primordiais tais como: os indivíduos, o fluxo urbano coletivo, o trânsito, a arquitetura, a paisagem, o clima, a cultura e os demais fenômenos decorrentes nesse espaço público onde tal intervenção se inscreve ${ }^{6}$. 
Em uma de suas intervençóes, o grupo realizou um "Rafting" - prática de descida em corredeiras em equipe utilizando botes infláveis e equipamentos de segurança - no Rio Maracanã, um dos principais rios da Tijuca que, pelo descaso dos poderes públicos e da própria sociedade, está poluído por esgoto e acúmulo de lixo. Assim, um problema ambiental grave, naturalizado por ter se tornado comum nos grandes centros urbanos, ganhou visibilidade na mídia pública.

Esta intervenção é uma produção que passa pela estética grupal e pela reinvenção do corpo como território radical para a reinvenção de si mesmo ${ }^{11}$. Atualmente o corpo jovem na cidade encontra-se em um dilema entre o corpo-objeto e o corpo-sujeito, ou seja, entre ser suscetível ao consumo e às imagens midiáticas ou estigmatizadas e marcadas pelos circuitos de segurança urbana ${ }^{4}$. Tanto de um lado como de outro, o corpo que resiste ao sistema de controle social produz agenciamentos coletivos que encarnam novas cartografias socioculturais através de práticas e linguagens emergentes e alternativas aos sistemas de dominaçãa ${ }^{12}$.

Compreender o processo de singularização nas intervençốes do sujeito deste estudo se faz necessário, quando o mesmo, se autoproclama Rizoma. Este é o nome do conceito desenvolvido por Deleuze e GuATTARI $^{13}$, na introdução do primeiro volume de Mil Platôs. Segundo esses dois autores, a conceituação de singularização se faz a partir da multiplicidade, da construção e desconstrução do agir no mundo, onde este é consequência da interpretação do sujeito na sociedade, formando identidades transitórias, mas coerentes com o desejo dos sujeitos de deixarem suas marcas na vida em sociedade.

O Rizoma é uma alusão a um tipo de raiz que pode ser tanto subterrânea quanto aérea (por exemplo, algumas plantas de manguezais), não tem um início ou fim definido, pois ao se ramificar produz outras ramificações e assim sucessivamente, se multiplicando. Outra forma mais conhecida de rizoma é a erva-daninha e a grama. A grama não tem início ou fim, correndo sempre pelo meio, adaptando-se à paisagem, recortando obstáculos. Como diz uma frase sempre repetida por DeLeuze ${ }^{14}$ : "sempre há gramas entre as pedras do calçamento" (p.41). Em uma de suas explicaçóes os autores dizem: "Não tem começo nem fim, mas sempre um meio, pelo qual ele cresce e transborda. Ele constitui multiplicidades"13 (p.31). Na visão filosófica do grupo, o Rizoma dá uma forma ao desejo de ser e de se fazer singular entre tantos outros grupos, moradores de uma grande área urbana na cidade do Rio de Janeiro. Eles imaginam que seu pensamento e agir únicos e originais se espalham pelos pensamentos de outros cidadáos, causando múltiplas novas percepçóes e possibilidades.

\section{Natureza / Cidade: \\ um ecossistema contemporâneo}

A celeuma quanto ao crescimento e "desenvolvimento" das cidades divide opiniôes. Contudo, o mais acertado quanto às alteraçôes sofridas é que sua topografia e geografia físicas e as relações sociais se adequaram com novas funçôes, diferentes de suas tradicionais.

O problema ambiental aparece num plano mais sensível com açôes cívicas e culturais, procurando conciliar o desenvolvimento social com o equilíbrio dos ecossistemas. Este movimento consciente dos recursos naturais finitos permite um exercício progressivo da cidadania através de uma nova cultura ecológica.

Nessa perspectiva, pensadores como Guattari no final da década de 80 ao problematizar tais questôes, vislumbram um mundo em deterioração, não apenas o físico (meio ambiente), mas assim como as relaçôes sociais e a própria subjetividade humana ao qual estariam ligadas de forma indissociável. Dizia o autor que não haveria uma verdadeira resposta à crise ecológica a não ser numa escala mundial, na qual houvesse condiçóes para uma autêntica revoluçáo política, social e cultural. Em sua visão, o meio ambiente natural de nossa sociedade está envolvido em três registros ecológicos no qual chamou de ecosofia, que é o equilíbrio do meio ambiente, das relaçôes sociais e da subjetividade humana ${ }^{15}$.

O conceito de natureza é social e cultural, portanto mutável, sendo assim a cidade é uma forma de natureza. Dessa forma, devemos pensar a cidade como um complexo ecossistema. A cidade não é completamente natural nem totalmente construída, ela não é "desnatural”, mas a transformação da natureza "selvagem" pela humanidade para servir as suas próprias necessidades (Spirn citado por SIRKIs ${ }^{16}$ ).

Esta nova configuração nos leva a compreender e desenvolver o elemento cidade, em uma re-ecologização do espaço urbano, trazendo para as cidades práticas de outros espaços numa progressiva deslocalização dos territórios tradicionais, tornando assim o tecido urbano objeto de novas apropriaçóes e de diferentes usos, deixando de ser apenas um espaço de circulação de trabalho e de habitação. Para esta nova configuração, a 'rua' começa a ser ocupada por práticas lúdico-esportivas ${ }^{17}$. Além disso, o ato esportivo deve se apresentar como um ato ecológico, pois há uma co-existência harmônica entre homem e natureza. 
Daí o grupo Rizoma ser um interessante objeto de estudo no que concerne esta configuração. Pois desenvolvem atividades esportivas que têm como características a prática em ambientes da natureza, porém eles o fazem no meio urbano (plurifuncional) e procuram em suas incursões, englobar atividades circenses, que carregam um aspecto artístico-cultural (multicultural), mas que são em sua essência atividades físicas. Congregam assim, em suas intervençôes, aspectos de uma nova conjuntura, em constante movimento e com difícil característica de conceituação, assim como nos mostram Deleuze e Guattari ${ }^{13}$.

A discussão de tornar a cidade mais "habitável" desta nova cultura urbana, através dessa re-ocupação

\section{Método}

Este estudo caracteriza-se como uma pesquisa qualitativa, com enfoque etnográfico, realizado através de um estudo de caso. A abordagem qualitativa de pesquisa envolve alguns pressupostos sobre a natureza da sociedade humana e sobre as ciências sociais, que devem ser explicitados para a compreensão teórica e metodológica de seus diferentes tipos de estudo. ERICKSON ${ }^{20}$ destaca que as unidades típicas de estudo da abordagem interpretativa são os grupos naturais ou as microculturas, caracterizados pela interaçáo recorrente de seus membros para a consecução de uma ação comum.

Cada microcultura possui uma forma particular de organizaçáo social, a interação regular dos indivíduos proporciona a construção de normas culturais, com as quais a ecologia social é organizada. As microculturas locais não são estáticas, e sim, dinâmicas, na medida em que o processo interpretativo é continuamente formativo pelo enfrentamento de situações do cotidiano; a mudança é constante ${ }^{21}$.

Diante do campo multifacetado (atividades esportivas, manifestaçôes culturais e comunicação - de massa e subversiva) escolheu-se o método etnográfico para o estudo da Intervenção Urbana Esportiva do grupo Rizoma. Pois ele nos fornece uma visão profunda, ampla e articulada de uma unidade social complexa, possui a capacidade de retratar situaçôes vivas do diaa-dia e, nos permite imergir no universo do grupo ou cultura pesquisada. Numa perspectiva interpretativa, ela clarifica os vários sentidos do fenômeno estudado e, com isto, procura modos de existência e interpretaçáo dos mesmos, na perspectiva dos nativos e dos estrangeiros - pesquisado e pesquisador ${ }^{1}$. do espaço público, se concretiza pela abordagem dos lazeres nomeadamente esportivos. Pois, temos de entendê-los como um fenômeno social de valor funcional diferente, mas não inferior ao trabalho, nem a ele subordinado. Subordinado sim, a uma necessidade de renovação emocional de equilíbrio entre o prazer e as restriçôes e controles civilizacionais evitando o empobrecimento humano ${ }^{18}$.

Não podemos nos preocupar com uma cidade compatível com os automóveis ou grandes edifícios, mas sim, que esta realidade se incompatibilize com o humano no plano ecológico, antropológico e social. A cidade deve ser cada vez mais casa do cidadáo, do homem que a edificou ${ }^{19}$, uma cidade acolhedora.

A pesquisa utilizou um conjunto de técnicas para coletar dados, e propôs-se a observar os valores, os hábitos, as crenças, as práticas e os comportamentos do grupo social em questáo, através de métodos como a observaçáo participante, a entrevista individual e a análise de documentos.

No decorrer da coleta de dados, foi fornecido aos participantes do grupo o termo de consentimento livre e esclarecido com informaçóes sobre a pesquisa; eles assinaram o termo, concordando assim com a sua participação. A pesquisa foi aprovada pelo Comitê de Ética da Universidade Salgado de Oliveira, e o procedimento adotado estava de acordo com a Resolução do Conselho Nacional de Saúde sobre medidas éticas em pesquisas que envolvem seres humanos.

A observação participante foi desenvolvida por um período de um ano e meio, em encontros com os indivíduos do grupo, em seu ambiente natural, acompanhando e participando de suas atividades (elaboração e realização), buscando descrever a situação, compreendê-la, e revelar os seus múltiplos significados. Para coletar e organizar essas situaçóes foi utilizado um diário de campo.

Foram realizadas entrevistas individuais com os cinco integrantes que compõem o grupo. As entrevistas foram semi-estruturadas, com a elaboração de um roteiro orientador previamente estabelecido como elemento facilitador de abertura, de ampliação e de aprofundamento da comunicação. As questôes do roteiro perguntavam sobre: a) o surgimento e a formaçáo do grupo; b) o objetivo do grupo; c) a razáo de filmar as atividades esportivas; d) o porquê da necessidade de mudança da rotina urbana; e) como acontece o 
processo de escolha e elaboração de uma intervenção; f) o porquê de utilizar atividades esportivas como instrumento para as intervençóes; g) qual a importância das atividades esportivas; e h) o impacto das intervençôes do grupo nas pessoas que o presenciam.

$\mathrm{O}$ roteiro foi um esquema básico não aplicado rigidamente, permitindo que o entrevistador fizesse as necessárias adaptaçóes. Pois além do respeito pela cultura e pelos valores do entrevistado, o entrevistador tinha que estimular o fluxo natural de informaçóes por parte dos entrevistados ${ }^{21}$.

$\mathrm{Na}$ análise documental foram analisados: a) reportagens em jornais e revistas; b) fotos; e c) vídeos, textos e fotos na internet sobre as intervençóes exercidas pelo grupo Rizoma, desde o seu surgimento. Foi analisado também a quantidade de acessos do "blog" do Rizoma e o número de citaçôes de outros "blogs" e "sites".

E devido a esta forma de análise, a das práticas comunicacionais mediadas por computador, recorremos a um tipo de etnografia chamada de etnografia virtual e sua adoção é validada neste estudo, pelo fato de que muitos objetos de estudo localizarem-se no ciberespaço e demandarem um instrumental apropriado para sua análise ${ }^{22}$. A etnografia também pode ser nomeada de netnografia e tem sido amplamente utilizada pelos pesquisadores da área do "marketing" e da administração. Preservamos o termo etnografia virtual, pois este é um termo mais utilizado pelos pesquisadores da área da antropologia e das ciências sociais. $\mathrm{O}$ espaço virtual permite que os dados sejam coletados à distância, facilitando a interpretaçáo e análise de dados localizados em um território desterritorializado, ou seja, sem uma área

\section{Resultados e discussão}

\section{Origem do grupo Rizoma}

Um grupo de amigos moradores do bairro da Tijuca no Rio de Janeiro tinha em comum a prática da escalada. Em especial quatro deles se encontravam com maior frequência: Diogo Vianna, Leonardo Coupey e os irmãos Leandro e Leonardo Chagas. O exercício dos fundamentos do esporte, assim como os desdobramentos costumeiros necessários para a prática da escalada - "trekking", trilhas, acampamentos ou expediçóes - fizeram com que eles conhecessem lugares pouco explorados dentro da cidade. Tal fato fez com que amigos em comum começassem a pedir que os levassem para poder física propriamente dita, mas que carrega sentidos dos sujeitos que os criam cotidianamente.

Assim, a partir de um determinado entendimento inicial, com este método foi possível ampliar o leque epistemológico deste estudo que perpassa pela comunicação e cibercultura. A utilização de uma etnografia virtual foi fundamental para a pesquisa, que foi realizada em um período no qual os jovens do grupo estavam tendo pouco tempo para se encontrar, e por isso não estavam planejando novas intervenções.

$\mathrm{Na}$ etapa de análise dos dados, à medida que os dados eram coletados, eram analisados, gerando relatórios, que serviram para expressar de forma clara a organização dos dados e as direçóes a serem seguidas. Essa etapa analítica e interpretativa foi elaborada através de uma reflexão deliberada e duradoura sobre a documentaçáo obtida. A reflexáo impóe o exame do observador sob seu ponto de vista interpretativo, sob suas fontes de teoria formal, sua formação cultural e seus valores pessoais ${ }^{23}$.

A coleta de dados foi dada por concluída no momento da saturação dos dados, ou seja, quando a aquisiçáo de informaçáo se tornou redundante ou a nova aquisição de informação foi diminuta ${ }^{24}$.

A necessidade de realizar este estudo por uma abordagem etnográfica revela-se quando BROMBERGER $^{25}$ admite que as atividades esportivas em suas diversidades, reproduzem valores essenciais e contraditórios das civilizaçóes que a modelaram. E que através de um trabalho etnográfico com sua observação e participaçáo efetiva do objeto estudado é possível "delimitar insuspeitáveis correlaçóes que escapam à consciência imediata” 25 (p.243).

conhecer lugares exóticos e bucólicos da cidade em que moravam.

A partir desse momento formaram um grupo informal de guias, que eles intitularam como Clim$b 4$. Aproveitando seus conhecimentos adquiridos através das atividades físicas que praticavam como, os fundamentos dos esportes de natureza, o reconhecimento geográfico dos terrenos para sua prática e os locais naturais dentro da cidade do Rio de Janeiro, aliaram a possibilidade financeira que isto poderia proporcionar a eles em futuras expedições.

A questão de filmar e fotografar as belas paisagens que encontravam em suas incursões nas trilhas com grupos de visitantes, não era novo. Antes mesmo do 
Climb4, os amigos já filmavam suas atividades escalando. A intenção era apenas registrar como foi a execução das vias (nome dos diferentes trajetos para uma escalada que se diferenciam pelo grau de dificuldade) e dos acontecimentos que viriam a ocorrer, como eles mesmos disseram "apenas por diversão, por brincadeira". Influenciados provavelmente por produçóes de vídeos amadores e profissionais estrangeiros de escalada ${ }^{g}$, os jovens começaram de forma lúdica a criar vídeos com trilha sonora e postar no "site youtube" recebendo boa repercussão por aqueles que os assistiam.

Concomitante a estes acontecimentos, alguns integrantes do grupo tinham um interesse pessoal em procurar ler autores da filosofia entre outras áreas das ciências humanas ou de assistir a palestras referentes a estas áreas. Os mesmos tinham um contato com o meio acadêmico por três de eles serem universitários, porém, nenhum era das ciências humanas. Uma das amigas que escalavam com o grupo, chamada Rebeca era estudante de filosofia e em conversas relacionava o que estavam fazendo com conceitos de Nietzsche, Spinoza, Deleuze e Guattari tais como a vontade de potência, de libertação do Estado e principalmente de Rizoma.

Assim cada vez mais, começaram a aparecer novos elementos corporais que fugiam da escalada. Os vídeos editados e postados sugeriam novas expressóes que aparentemente não se enquadravam em uma atuação normal de um grupo de guias. Citaçóes de autores da filosofia ou a utilização de músicas fizeram com que o grupo percebesse que o nome Climb perdia o sentido original e indicava que algo estava mudando no sentido inicial do grupo de apenas praticar a escalada e fazer expediçóes para procurar novas trilhas.

Nesse momento surge o nome de Projeto Rizoma. Como se interessavam por filosofia, o conceito Rizoma se integrava aos anseios que eles sentiam e necessitavam mostrar a partir daquele momento. $\mathrm{O}$ "divisor de águas" que seria a mudança de caráter do grupo foi a expedição ao Forte da Laje.

A partir daí criaram um "blog" para o grupo (canalrizoma.blogspot) onde pela primeira vez apresentam-se como Rizoma e com uma foto de três integrantes olhando do Forte da Laje para a cidade do Rio de Janeiro, com os seguintes dizeres: "Após a conclusão da série 'Ratier - A RATOEIRA', o grupo Climb4 começará um nova série chamada RIZOMA, onde arte, esportes radicais, música e viagens se encontram formando um programa que desafia seus instintos." A apresentação gráfica do "blog” consiste em uma ilustração com a foto de um local gramado, que é uma alusão ao conceito tirado da botânica, e a palavra Rizoma embaixo da foto. A apresentação do grupo está descrita da seguinte maneira:

O Rizoma é um grupo de praticantes de esportes radicais e circenses que usam suas habilidades em intervenções e missões que desafiam a rotina urbana, chamam a atenção e interferem em questões sociais, políticas e ambientais de forma criativa e surpreendente. O grupo carrega em si uma nova forma de encarar a realidade.

\section{As ações do grupo}

Com o fim do Climb4, o site do grupo sai do ar, assim não foi possível ter conhecimento dos vídeos que podiam ser acessados nesse site. Uma forma encontrada para possibilitar uma visão de maior abrangência acerca dos significados, símbolos, estéticas, discursos entre outros elementos, recorremos aos canais pessoais dos componentes do grupo no "site youtube" assim como buscamos informaçóes oriundas dos próprios componentes do grupo. Como o grupo Rizoma é oriundo do Climb4, se faz necessário iniciar os comentários sobre os vídeos no "site youtube" que ainda estão disponíveis na rede, postados por Diogo Vianna e Leonardo Chagas, para que se possa compreender a transição entre a formação de um grupo a outro.

Os vídeos de escalada do Climb4 têm em comum apresentar o desempenho do escalador, mostrando os percursos em uma via e sempre alcançando o objetivo. Os vídeos do Rizoma apresentam outras atividades como a circense, por exemplo, e não intencionam demonstrar a habilidade na via de escalada, mas uma ideia.

O que se presencia nesse momento é o confronto com uma nova forma de expressão, é a constituição dos complexos de subjetivação: indivíduo-grupovídeo-trocas múltiplas, que oferecem a eles (assim como a quem assiste) possibilidades diversificadas de recompor uma corporeidade existencial, e "sair de seus impasses repetitivos e, de alguma forma, de se re-singularizar"26 (p.15).

Esta atitude vai ao encontro e se coaduna com os eventos de formação do grupo tanto no Climb4 quanto no Rizoma. No que diz respeito ao caráter físico e filosófico, por não se deixarem perturbar pela eventual dificuldade em desenvolver uma prática, o que existe para os integrantes do grupo é a possibilidade de desenvolver suas habilidades e assim desestruturar uma cadeia institucionalizada na estratificação social ou econômica. As adversidades encontradas sáo novas possibilidades no percurso de 'desviar' o que para eles é socialmente imposto. 
Pode ser percebido em suas falas e atitudes um espírito álacre e transgressor em que verdades institucionalizadas, por diversas formas de controle (religioso e econômico), não se sustentam a partir do momento em que se vêem como seres corporais. $\mathrm{Ou}$ seja, seus corpos e mentes não são dicotomizados e suas açôes nada mais são que a resposta para discursos reducionistas e sectários do esporte ideologizado em um pensar capitalista.

As ideias para as ações são tratadas entre eles em "reuniôes" não formais. Até o ano de 2010 disseram que marcavam de se encontrar e pensar novas ações, porém sem dia e horário rígido; era entrar em contato uns com os outros e "realizar a reuniâo". Pela dificuldade de horários no ano de 2011 ficou ainda mais raro o encontro de todos. No entanto, em conversas informais ou durante as entrevistas, nenhum deles sequer falou na ideia de que o grupo está acabando ou pode acabar.

Ainda enquanto uma microcultura fica difícil definir quantas pessoas participam do grupo. Este é aberto a qualquer pessoa que queira participar de suas atividades, sejam elas na prática das atividades esportivas, intervençôes ou nas discussôes sobre filosofias e outros assuntos que envolvam o grupo.

Não há necessidade de que todos estejam reunidos para criar e discutir novas açóes; entretanto estas só são realizadas se todos tiverem o conhecimento, se for possível a ação. Não há obrigatoriedade de que todos participem e somente participam aqueles que quiserem.

A forma como o grupo age pode parecer desorganizada, mas é resultado da ideia de Rizoma enquanto conceito filosófico que permite e incita uma configuração, em nossa opinião, criativa. Pensamos que sua multiplicidade de interesses, elementos constitutivos de sua manifestação cultural através de atividades esportivas ou corporais, desenvolve um elo fraternal que une os integrantes do grupo e cria uma rede de amizade com outras pessoas. Essa multiplicidade também favorece que a liberdade vivenciada pelos jovens escape a uma subjetividade serializada e potencializa ramificaçôes em diferentes caminhos, permitindo perceber novos ângulos em sua atuação como grupo.

Pudemos apreender que a referência do grupo é a ocupaçáo dos espaços por ideias, seja numa esfera pública (praças, ruas ou internet) ou privada (meios de comunicação corporativos) que venham dar-lhes o espaço necessário para, através de seus meios, divulgarem suas crenças. Essas concepçóes fundamentam uma luta ou ideal, com característica ideológica, já que os meios de difusão de informação beneficiam-se de um poder simbólico poderoso.
Dessa forma, por que eles não poderiam utilizar seu instrumento (as atividades corporais), que carregam signos tão fortes, para criar novos olhares para o que eles têm a dizer? Compreendemos que para eles o registro além de um modo de guardar um momento é um modo de potencializar o evento. Assim, eles pensam na utilização das mídias de massa como estratégia para açôes que desloquem o olhar do espectador para uma direção náo comum.

A utilização e ocupação dos espaços urbanos como estrutura física para as intervençóes urbanas esportivas, que o grupo Rizoma cria, expressa uma compreensão de cidade em seu aporte "natural", ou seja, seu habitat. Se possibilitarmos uma visão das ciências biológicas, para as quais a interação em uma determinada região por diferentes seres vivos que sofrem influência de meios abióticos é um ecossistema, então a cidade em sua configuração contemporânea pode ser entendido como o principal ecossistema humano.

E é nesse meio ambiente urbano que o grupo realiza a prática de esportes de natureza (mesmo que não seja o local comum para a prática escolhida), aproveita-se das habilidades desenvolvidas nesses esportes (além de outras atividades) e elabora as suas intervençóes. Essas, com o suporte dos conceitos filosóficos conhecidos pelos integrantes do grupo, legitimam suas açôes nos espaços públicos $\mathrm{e}$ nas mídias, em especial na digital. Mídia esta que possibilita em um distinto espaço-tempo reverberar e produzir diferentes afetos nos espectadores que não puderam presenciar as atividades "in loco".

Presenciamos esses elementos que náo podem ser categorizados em escalas de prioridade, pois não há uma esquematização ou regras a serem seguidas na criação das intervençóes. Elas surgem pelas sensibilidades dos integrantes ao que ocorre a sua volta, indo ao encontro do principal conceito filosófico a que se apegam e dá nome ao grupo: Rizoma. Uma raiz sem um centro e um início aparente, tudo nela é meio, pois se ramifica para todos os lados e constantemente de diferentes pontos, podendo existir mesmo sem o ponto que lhe originou. $\mathrm{E}$ assim deve ser para eles compreendida uma forma de viver, pensar e agir.

A seguir apresentamos alguns trechos de falas dos entrevistados sobre sua prática. A categoria de análise que emergiu após a transcrição das entrevistas foi a da intervençáo urbana.

A intervenção urbana é justamente [...] Primeiro basicamente é por quê? Eu sinto muita vontade de fazer algumas coisas quando estou andando na rua, por exemplo, Le parkour, dá muita vontade de tá passando numa praça vê 
um monumento ou alguma estrutura que dá vontade de subir, dá vontade de pular, de girar, dá vontade de fazer tudo isso (E1).

A rotina urbana que está dentro da gente [...] A rotina de vida né. E ela está muito mais baseada em certo e errado do que necessariamente do que é saudável ou não. Então o que o Rizoma procura fazer nunca é o errado, pode beirar valores moralmente errados criados pela sociedade, mas a utilização do espaço público de maneira saudável, eu acho que é realmente o ponto (E3). Essa quebra de rotina pela intervenção traz ali um sorriso na pessoa que ela não daria naquele horário, traz um pensamento diferente de que ela está acostumada a ter. E isso modifica a pessoa, e a gente acha, que traz um bem principalmente pra gente e pra sociedade também como um todo e a gente gostava de fazer essa modificação (E2).

Podemos afirmar que a categoria central mencionada acima e ressaltada nas falas dos participantes, é coerente com a filosofia do grupo. Por outro lado, considerando que esse estudo tem como sujeito de pesquisa um grupo de intervençóes urbanas que, para as apreensóes de seus discursos e subjetividades, utiliza ferramentas comunicacionais para suas açóes o tempo real e virtual. Para isso o virtual náo pode ser compreendido como algo etéreo ou abstrato, mas, concreto. Que assim como o real sofre influências e influencia na subjetividade de quem participa ou de quem observa. Feres $\mathrm{Neto}^{27}$ discorre sobre o tema lembrando Pierre Lévy:

Logo no início do seu trabalho $\mathrm{O}$ que é o

virtual, Lévy desfaz a noção, tão difundida, de que o virtual se opõe ao real. A palavra virtual vem do latim medieval virtualis, derivado por sua vez de virtus, força, potência. Na filosofia escolástica, é virtual o que existe em potência e não em ato. $\mathrm{O}$ virtual tende a atualizar-se, sem ter passado, no entanto, à concretização efetiva ou formal. A árvore está virtualmente presente na semente. Em termos rigorosamente filosóficos, o virtual não se opõe ao real, mas ao atual: virtualidade e atualidade são apenas duas maneiras de ser diferentes ${ }^{27}$ (p.8, grifo do autor).

Dessa maneira, esse estudo não pode apenas se fixar ou limitar em uma noção de realidade para as intervençóes, mas deve se debruçar no processo de virtualização das açôes do grupo e na potência desencadeada por elas. Os diversos elementos que o grupo envolve em seus vídeos e fotos como trilha sonora, títulos e epígrafes, edição, "layout" da página entre outros, produzem sensibilidades táo diversas nos que navegam pela internet e em seu "blog", tanto quanto se observassem as ações em tempo real. Ou seja, nesse espaço eles podem criar e atualizar algo que já é novo, potencializando as suas ações através de diversos outros instrumentos que não seriam possíveis no mundo real.

Esses novos ativistas no ciberespaço transformaram na prática o sentido da palavra "resistência", percorrendo e ramificando-se em um processo evolutivo nas redes da internet, ao potencializar discussóes e conformaçôes em novas configuraçôes libertárias advindas da sua prática nas ruas. Para aqueles que se organizam a partir de seus ideais não é somente a paixão do embate com o poder institucionalizado e seus dispositivos de controle como ponderou ANTOUN ${ }^{28}$, resistir tornou-se também inventar os movimentos através dos quais os modos autônomos de viver e governar a própria vida possam ser ao mesmo tempo as formas de lutar e se manifestar publicamente.

O grupo Rizoma, manifestando-se por formas da cultura esportiva, demonstra ao público o quanto é viável pensar e agir fora das instituiçóes hegemônicas esportivas. Uma expressão cultural não se pode manter enclausurada ou aprisionada pelos meios de comunicação de massa que tentam vender uma configuração de uma pequena gama de atividades esportivas referentes ao alto rendimento como confirmam os autores:

Quem oferece o modelo esportivo a ser seguido é o esporte praticado sistematicamente por uma minoria de indivíduos obstinados. Ainda mais se considerarmos a farta e onipresente difusão da imagem pelos meios de comunicação do esporte praticado por esses esportistas. A presença insistente dessas imagens acaba reforçando todo o imaginário popular em torno dessas atividades. (...) E é nesse sentido que a concepção esportiva adotada como modelo hegemônico é aquela vinculada as suas instituições. Somente nas instituições encontramos praticantes com perfil e com capacidade técnica de realização dos feitos adequados à linguagem midiática. É esse tipo de praticante, portanto aliada a uma poderosa indústria da cultura, o principal responsável (direta ou indiretamente) pela popularização desses esportes enquanto um símbolo de consumo ${ }^{29}$ (p.94).

Talvez também por isso o tecido urbano venha sendo tomado, quase que "arrendado", em sua totalidade, pela esfera do privado na presença maciça dos shoppingscenters ao invés das lojas de rua, da supervalorização dos transportes individuais aos coletivos, e dos espaços privados para as atividades físicas às áreas de lazer públicas. Podemos assim ler de forma subscrita como valores agregados a uma homogeinização do indivíduo, em que o mesmo "necessita" consumir em diversos 
momentos de sua vida social e de lazer com produtos e marcas "fetichizadas".

O grupo em suas ações procura sensivelmente perceber a cidade e suas áreas (física e virtual) em sua abrangência, tanto em seu controle e segurança com seus muros ou moderadores de sites, assim como nos espaços públicos e livres de grades, e perniciosamente, às vezes, esquecidas pelo poder público. Nestes locais far-se-âo seus dispositivos de transgressão inventiva ou como os mesmos mais de uma vez nas entrevistas disseram "formas de libertar o corpo".

Podemos discorrer que o Rizoma em sua concepção quer demonstrar e mostrar, que é preciso tomar a cidade de surpresa e oferecer de uma nova opção com a utilização do próprio movimento do corpo. Que o espaço deve ser apropriado, produzido e reproduzido de modo libertário através das atividades corporais, sejam elas atividades esportivas ou não. Pois como eles mesmos projetam, os espaços públicos devem ser ocupados e vivenciados das mais diversas formas possíveis, pelas atividades físicas ou por outras formas de manifestaçōes. O importante como afirmou Pedro, "é que as pessoas se conheçam como indivíduos corporais e que seu meio é a cidade, é a praça, é a rua”.

$\mathrm{Na}$ fala de um de seus participantes:

A gente não é um grupo revolucionário. $\mathrm{O}$ caráter do grupo, a filosofia do grupo já é tão a desinstitucionalização, é tanto a desestruturação, é tanto a questão de ser rizomático é tanto a questão de intervir que seria totalmente contra a lógica do que a gente criou ou do que foi criado na gente. De se pegar aquilo e criar um programa de televisão, totalmente não interventor.... perderia totalmente o programa por si só... não ia dar certo ou ia pegar uma outra linha e tudo. O que dá certo no Rizoma, porque a gente quer que dê certo, que esses afetos nas pessoas e na sociedade, tem que ser esse caráter, essa chama interventora, não adianta. Não dá para parar isso.

Os atores sociais do Grupo Rizoma pensam a cidade como um território não apenas de moradia, mas uma entidade resultante de variáveis demográficas, forças de diversas esferas sociais e de interesses políticos e econômicos. Esta é um cenário e ponto de encontro, onde diferentes redes sociais mesmo desprovidas de bens comuns para seu lazer produzem ramificações de sociabilidade através de atividades corporais levando-nos a pensar escolhas distintas da visão hegemônica, que se propóe como natural, de como deve ser o esporte na cidade.

A recusa generalizada que se observa hoje em aceitar essas novas práticas como compondo mais uma manifestação esportiva, deve-se, provavelmente, a esse inexorável atrelamento às instituiçóes esportivas hegemônicas, sendo estas últimas, decisiva e verdadeiramente influenciadas por uma excessiva valorização da competição. Traço que segundo dizem, não se faria presente nos esportes na natureza ${ }^{29}$ (p.31).

Como autores da filosofia apareceram em todas as falas dos integrantes do grupo, e sáo citados como base conceitual para existência do grupo, procuramos em alguns deles pontos de apoio para compreender o ponto de vista e o que reflete suas intervençóes. No momento debruça-mo-nos sobre o texto de DELEUZE $^{14}$ que disserta sobre a passagem da sociedade disciplinar para a sociedade de controle, onde os dispositivos disciplinares de encarceramento foram substituídos por novas modalidades de controle.

Se prisóes, escolas e manicômios aparentemente esgotaram arquitetonicamente como instrumento de poder disciplinar, a arquitetura pode ser encarada como uma célula ou uma peça de algo maior - o urbanismo - que está sendo usado a serviço de interesses de alguns em detrimento de outros. E assim, quando se fala sobre renovaçóes urbanísticas na cidade vendese uma ideia de uma vida melhor para a sociedade em geral. Como exemplo acontece na cidade do Rio de Janeiro mudanças urbanísticas para a Copa do Mundo e Olimpíadas, que resultam em desalojamentos de pessoas, como na favela da Mangueira ou em diversos bairros periféricos para dar lugar a novas vias de acesso. Essas pessoas são realocadas longe do centro urbano e dos olhos dos turistas que passarão do aeroporto do Galeão a outros pontos da cidade.

Quando o Rizoma propóe 'mudar a rotina da cidade', faz pensar em especial nesse aprisionamento do corpo por um urbanismo sectário que priva os espaços comuns frente ao privado. Suas intervençôes instauram um levante através das atividades corporais não capturadas por instituiçóes hegemônicas do esporte. Em suas apropriaçóes e improvisaçóes dos espaços, legitimam de forma performática aquilo que foi ou não projetado para uma determinada ação (uma escada ou muro náo foram feitos para serem escalados ou percorridos em dois apoios). Mas, são essas açóes e experiências que reinventam a utilização dos espaços públicos.

Apresentar novos modelos de práticas de atividades esportivas alocadas em ambientes que não seriam os próprios deles demonstra sua visão do esporte enquanto uma cultura dinâmica em consonância com as mudanças contemporâneas. Eles encontram novas possibilidades e propõem uma 
discussão das práticas esportivas que muitas vezes são determinadas por demandas instituídas por uma estratificação social.

É importante salientar o quanto isso vai ao encontro do problema proposto neste estudo acerca da visão hegemônica do esporte que prioriza apenas duas formas de esporte: o de alto rendimento e o para manutenção da saúde, em detrimento das atividades esportivas serem vistas como modos de expressão humanos na forma de uma manifestação cultural e assim possibilitando diversas e múltiplas leituras. Não se pode tornar para si, como tentam as instituições esportivas através da mídia, que o esporte ou o jogo deve ser feito em lugares específicos ou para fins exclusivos. Como afirmam Dias e Alves Junior ${ }^{29}$ : "Devemos então fugir da tentativa da canonização de uma determinada forma de expressão do esporte e compreender que essa manifestação cultural, como todas as demais, é fluída” (p.31).

Poder-se-ia dizer que o grupo pondera, já que tratam de intervençóes por modo de resistência, acerca de um caráter de questionamento radical no trato com o ambiente urbano. Contudo, seu modo de resistência utiliza experiências sensíveis e lúdicas no espaço urbano procurando construir, nas suas apropriaçóes, outras experiências nos indivíduos que observam suas açóes ou apenas as percebem em seu passar pelas calçadas ou em "blogs" e "sites" de vídeos.
As formas comunicacionais da linguagem humana virtualizam o tempo real, os acontecimentos atuais, as coisas materiais e as situaçóes em curso. As intervençôes urbanas nas mídias digitais proporcionam uma ferramenta que possibilita potencializar ideias e pensamentos os tornando concretos, já que surtem um efeito nos afetos do indivíduo.

A tentativa de diminuir as ações do grupo dandoas apenas uma concepção virtual, na qual implicaria a negação do corpo e dos desejos reais, é implodida ao percebermos que a memória e o pensamento são amplificados através de cabo ou redes "wireless" e convertidos em informação atual e imediata. Disponível na internet, esta mobiliza e afeta os corpos que, não passivos, procuram formas novas ou antigas de manifestar a sua alegria ou descontentamento em novas conformaçóes de se viver.

As intervenções corporais dos jovens integrantes do grupo em ambientes públicos suscitam um escape simbólico das imagens hegemônicas do corpo impetrados em ambientes sectários e privados. Os componentes do grupo buscam a experiência corporal urbana, e suas diversas facetas: o corpo urbano e o corpo humano, o corpo arte e o corpo político, ou seja, o corpo e as suas potencialidades. No caso específico do Grupo Rizoma, as intervenções urbanas esportivas são uma forma de micro-resistência em oposição ao corpo mercadoria e corpo espetáculo.

\section{Notas}

a. Autonome A.F.R.I.K.A. Gruppe. Grupo anônimo de comunicação de guerrilha são ativistas e não-artistas que vivem nas periferias da Alemanha e em 1997 publicou o AFRIKA Communnication Guerilla Handbook. Referem-se a uma tentativa de provocar efeitos subversivos através de intervençôes no processo de comunicação. Eles podem ser distinguidos de outras classes de ação política, porque não se baseiam na crítica dos discursos dominantes, mas na interpretação dos sinais de uma maneira diferente. Site: www.republicart.net/disc/artsabotage/afrikagruppe.

b. Tanto o movimento Dadá-Berlim, também conhecido como dadaísmo, quanto o surrealismo se caracterizam por serem movimentos ligados à arte, contestadores, subversivos, de vanguarda, e críticos da cultura vigente. O dadaísmo se inicia em 1916, com a criação do Cabaré Voltaire, em Zurique. O surrealismo é um termo cunhado por André Breton. O primeiro manifesto do movimento surrealista, em 1924, aborda uma supra-realidade, na qual não há contradição entre sonho e realidade. Sites: http://www.itaucultural.org.br/aplicExternas/enciclopedia_IC/index. cfm?fuseaction=termos_texto\&cd_verbete=3651 e http://www.itaucultural.org.br/aplicExternas/enciclopedia_IC/ index.cfm?fuseaction=termos_texto\&cd_verbete $=3650$.

c. Stickers são papeis adesivos produzidos artesanalmente e em número suficiente para serem espalhados pela cidade, criando percursos, apropriaçôes territoriais e reconhecimento em áreas distintas. Esses adesivos são considerados vantajosos por sua versatilidade e fácil aplicação. Representante de uma nova vertente da filosofia Do it yourself, não há limite de tamanho e as figuras são feitas com caneta, xerox, serigrafia ou tintas plásticas num forte diálogo com as artes gráficas ${ }^{4}$.

d. A técnica do stencil é um método de graffiti que recorre a um molde com um desenho ou texto pré-preparado, sobre o qual a tinta é colocada, criando uma impressão no suporte, em geral paredes, e que permite a reprodução rápida de imagens como mecanismo de comunicação semelhante ao da publicidade ${ }^{30}$. 
e. Os Teatros de Guerrilha são grupos não comerciais, que através de apresentaçóes gratuitas ao ar livre, procuram tocar e mobilizar o espectador com espetáculos alusivos a condição do país debatendo, criticando, demonstrando, centrados no plano da denúncia social e política ${ }^{31}$.

f. Eles puseram esse nome, pois apresentava um duplo significado um deles seria a tradução das palavras: climb em inglês significa escalar e four, quatro, demonstrando assim o número de pessoas que compunham o grupo. E podia ser uma expressão, devido ao numeral quatro ter um som parecido com a palavra for que em português é para. Podendo o nome ser entendido como: climb for que, traduzindo seria escalar para.

g. Desde 2001, na cidade do Rio de Janeiro, acontece a Mostra internacional de filmes de montanha que se encontra hoje em sua décima primeira edição. É comum encontrar na internet vídeos amadores onde escaladores aparecem demonstrando suas performances concluindo determinadas vias.

\begin{abstract}
Sports urban intervention: an ethnographic study about the Rhizome group

The aim of this study was to analyze alternative forms of sports actions performed by a group of youngsters who intend to counteract reductionist views of sport related to contemporary capitalism and, in this way, present their critical view of system through sports urban intervention. The research used as the qualitative methodology, an ethnographic case study, employed the following instruments of data collection: participant observation, individual and group interviews and document analysis. Since the sport provides us aesthetic possibilities in different dimensions, and not only the one consumable by the market, we can think of it as a cultural manifestation and that its uniqueness is not confined only in the sports entertainment industry.
\end{abstract}

KeY WoRds: Culture; Case study; Sport; Public space.

\title{
Referências
}

1. Geertz C. A interpretação das culturas. Rio de Janeiro: LTC; 1989.

2. Daolio J. Educaçáo física e o conceito de cultura. Campinas: Autores Associados; 2007.

3. Pires GL. Breve introdução ao estudo dos processos de apropriação social do fenômeno esporte. Rev Educ Fís/UEM. 1998;9:25-34.

4. Oliveira RCA. Estéticas juvenis: intervençôes nos corpos e na metrópole. Com Mídia Consumo. 2007;4:63-86.

5. Mazetti H. Entre o afetivo e o ideológico: as intervençóes urbanas como políticas pós-modernas. Eco-Pós. 2006;9:123-38.

6. Barja W. Intervenção/terinvenção: a arte de inventar e intervir diretamente sobre o urbano, suas categorias e o impacto no cotidiano. Rev Ibero-Amer Ci Inf. 2008;1:213-8.

7. Gruppe AA. What about communication guerrilla. In: Richardson J, organizer. Anarchitexts: voices from the global digital resistence. New York: Autonomedia; 2003. p.86-92.

8. Home S. Assalto à cultura: utopia, subversão e guerrilha na (anti)arte do século XX. São Paulo: Conrad; 1999.

9. Arantes AA. O que é cultura popular. São Paulo: Brasiliense; 1990.

10. Pires G. Cultura esportiva e espetáculo midiático. Canto: Instituto Contato [citado 10 ago 2010]. Disponível em: http://www.institutocontato.org.br/noticias.

11. Ganter R. La ciudad tatuada (de jóvenes, cuerpos, architexturas y escrituras). In: Zarzuri R, Ganter R, organizadores. Jóvenes: la diferencia como consigna. Santiago: CESC; 2005.

12. Foucault M. Microfísica do poder. Rio de Janeiro: Graal; 1979.

13. Deleuze G, Guattari F. Mil platôs: capitalismo e esquizofrenia. São Paulo: Editora 34; 1996. v.3.

14. Deleuze G. Conversaçóes. Rio de Janeiro: Editora 34; 1992.

15. Guattari F. As três ecologias. Campinas: Papirus; 1990.

92 • Rev Bras Educ Fís Esporte, (São Paulo) 2015 Jan-Mar; 29(1):81-93 
16. Sirkis A. Ecologia urbana e poder local. Rio de Janeiro: Fundação Onda Azul; 1999.

17. Constantino JM. Desporto, cidade e natureza: espaço público e cultura ecológica. In: Da Costa LP, organizador. Meio ambiente e desporto: uma perspectiva internacional. Porto: Faculdade de Ciências do Desporto e Educação Física; 1997. p.116-24.

18. Elias N, Dunning E. Em busca da excitação. Lisboa: Difel; 1992.

19. Bento JO. Desporte cidade natureza: introdução ao tema. In: Da Costa LP, organizador. Meio ambiente e desporto: uma perspectiva internacional. Porto: Faculdade de Ciências do Desporto e Educação Física; 1997. p.94-102.

20. Erickson F. Qualitative methods in research on teaching. In: Wittrock M C, organizer. Handbook of research on teaching. New York: MacMillan; 1986. p.119-61.

21. Minayo MCS. O desafio do conhecimento: pesquisa qualitativa em saúde. São Paulo: Hucitec; 1996.

22. Montardo SP, Rocha PJ. Netnografia: Incursões metodológicas na cibercultura. Rev E-compós. 2005;4:1-22.

23. Martucci EM. Estudo de caso etnográfico. Rev Bibliotecon. 2001;25:167-80.

24. Bogdan R, Biklen S. Investigação qualitativa em educação: uma introdução à teoria e aos métodos. Porto: Porto Editora; 1994.

25. Bromberger C. As práticas e os espetáculos esportivos na perspectiva da etnologia. Horiz Antropol. 2008;14:237-53.

26. Lévy P. O que é o virtual? São Paulo: Editora 34; 1996.

27. Feres Neto A. Produção de subjetividades, subjetivação e objetivação: algumas contribuiçôes de Félix Guattari e Pierre Lévy para a educação física. Motrivivência. 2001;17:6-17.

28. Antoun H. Jornalismo e ativismo na hipermídia: em que se pode reconhecer a nova mídia. Rev FAMECOS. 2001; 16:135-48.

29. Dias CAG, Alves Junior ED. Entre o mar e a montanha: esporte, aventura e natureza no Rio de Janeiro. Niterói: EdUFF; 2007.

30. Queiroz KG. Coimbra por stencil: algumas reflexôes sobre os graffiti stencil no entorno da Universidade de Coimbra. Cabo Trab. 2010;4:1-21.

31. Mostaço E, Seidler Júnior EH. A encenação no Brasil entre os anos de 1967 e 1974: o tropicalismo no teatro. Rev Pesq. 2004;1.

\begin{tabular}{r|r} 
ENDEREÇo & \\
Renata Osborne & \\
Universidade Salgado de Oliveira & \\
Mestrado em Ciências da Atividade Física & Recebido para publicação: 17/10/2013 \\
R. Marechal Deodoro, 217 - bloco C - 20. andar & 1a. Revisão: 02/o8/2014 \\
24030-06o - São Paulo - SP - BRASIL & 2a. Revisão: 20/10/2014 \\
e-mail: pgcaf@nt.universo.edu.br & Aceito: 21/10/2014 \\
&
\end{tabular}

